\title{
A study on the effects of productivity of human resources in banking network and work ethics
}

\author{
Zahra Vazifeh $^{\mathrm{a}}$ and Masomeh Kiani Ghaleh Nou ${ }^{\mathrm{b}^{*}}$
}

${ }^{a}$ Assistant professor in Faculty of management from University of Sistan and Baluchestan, Zahedan, Iran ${ }^{b}$ MA student of Human Resource Management, University of Sistan and Baluchestan, Zahedan, Iran

\section{H R O N I C L E}

\section{Article history:}

Received December 2, 2013

Accepted 8 May 2014

Available online

May 152014

Keywords:

Dependability

Work ethics

Human resources productivity

Effectiveness

Efficiency \begin{abstract}
A B S T R A C T
Today, human resources are considered as the most important assets of any organization. Generally, human being has specific ethical features on personality characteristics forming the attitude, speech and behavior. It is possible that some factors create different attitudes, speech and behavior among people who are in one particular position. These human characteristics influence the efficiency and effectiveness of organization. The present study aims to investigate the relationship between work ethics and human resources productivity in banking network of city of Zahedan, Iran. The study chooses a sample of 236 employees who worked for different banks in city of Zahedan, Iran in 2013. To analyze the data, Pearson correlation test, Friedman ranking and independent t-test were used. The results show that there was a significant association between work ethics components and productivity (efficiency and effectiveness) of human resources.
\end{abstract}

\section{Introduction}

Ethics is normally considered as a set of mental and inner attributes of human being, it is also manifested as the behaviors arising from the inner moods of human being and it is defined through its effects. Continuing a specific behavior, the reason is that this behavior is an internal root in the depth of one's soul called mood and ethics. Ethics is also considered at individual behaviors limit. However, when individual behaviors are prevalent in the society or social institutions, they are turned into a type of collective ethics rooted in the society culture (Tulayi, 2008). Ethics philosophy indicates philosophical issue regarding ethics including three fields of meta-ethics, normative ethics and applied ethics (Ronaghi \& Feizi, 2012). By acquiring experience for some years, many people find that if a country attempts to have a developed economy and wins in the competition field, it should have efficient, specialized, motivated and innovative human resources (Nosratpanah et al., 2012). Ethics management is defined as a set of ethical principles and standards directing behavior

\footnotetext{
*Corresponding author.

E-mail addresses: kiyani152@gmail.com (M. Kiani Ghaleh Nou)
} 
and it has special importance in state management (Larbi, 2001). There are various studies performed regarding the consideration of ethics in state management and organizations management. The improvement of ethics in public sector plays essential role on improving the quality of the presented services from the public organizations and increasing the organizations in public (Alvani \& Danayifard, 2001). If work ethics is present in the work life of human being, working will be good with job satisfaction and self-actualization on one hand and people satisfaction and actualization and development of works on the other hand (Salajeghe \& Sistani, 2010). Ethical climate is a type of work-space reflecting the organization rules and dealing with ethical results (Martin \& Kulen, 2006). Establishment of ethical behaviors in an organization depends on the respect of the policy makers and managers to ethical values. Employees are the most valuable resources of any organization. Today, human resources are considered as the main assets of organizations and its competitive advantage. It can be said that worker productivity is not working hard and it is working with better planning and more thoughts and increasing creativity (Khatami Firoozabadi \& Heidari, 2012).

The management mission and objectives of any organization is associated with effective application of the various resources such as labor force, capital, materials, energy and information. Optimal implication of human resources is of great importance in this mission (Hamidifar, 2009) and human resources are some of the most important productivity factors in an organization. The most important factor to achieve optimal organization productivity is efficient resources. By increasing competition and development of human resources development methods, the organizations attempt to keep the talented employees and empower them to show their performance (Khatami Firoozabadi \& Heidari, 2012).

To do organizational affairs, the organizations, in addition to organizational and legal criteria, need a set of ethical and value guidance helping them in administrative behavior to create coordination and unity of procedure to move towards good collective and general method. Normally, the organization members accept the values relevant to their lives. The organizations are obliged to create an environment of ethics and values in organizations (Karimi et al., 2010). As organizational ethics are important in social life, efficiency and effectiveness of organization. In addition, due to the great emphasizes of the authorities of the country in development of work and production culture and recognition of elimination of work negligence and indifference to work, one of the duties of the authorities in the country is to prepare for hard working, creativity, innovation, commitment and responsibility in great work community. According to the views of the most of the economic experts, productivity in Iran is very low and the lack of suitable work ethics and culture in the society is a socio-economic problem. Thus, it is decided to identify the work ethics components based on the underlying value system in the society in which we can evaluate the ethics of people in the organization and improve them. The present study aims to evaluate the relationship between work ethics and productivity (efficiency and effectiveness) of human resources. In other words, this study tried to understand the relationship between work ethics and efficiency and effectiveness of the employees of bank network in city of Zahedan, Iran.

\section{Review of literature}

Eltantawy et al. (2009) conducted a study in Europe regarding health and management productivity and showed that work life style as a psychological factor in work place can increase productivity of the employees. Tulayi (2008) performed an empirical investigation on 123 pharmacology employees in Malaysia and reported that behavior could be affected by successful acts of the managers and work experience was effective on ethical behavior of the employees. However, gender and education and professional ethics had no significant effect on ethical behavior of the employees. Haghiri (2009) defined the relationship between managers' ethics dimensions including personal, organizational, social and legal ethics with organizational commitment and job attachment of the education employees. Okpara and Wynn (2008) investigated the impact of ethical climate on job satisfaction, 
and commitment in Nigeria and reported that there was a significant association between organizational work ethics and job satisfaction. Pournaghdi (2009) investigated ethical issues in information technology (IT) based organizations. Sohrabi and Khanlari (2009) investigated the relationship between ethics IT and citizenship behavior.

\section{Theoretical framework of the study and research conceptual model}

The proposed model of this paper is design based on conceptual model originally developed by Salajeghe et al. (2010) and Ghahremani Gholi Gerochian (2012). The present study investigates the relationship between work ethics and human resources productivity and dependability, hard work, healthy, human and religious relations at work place (consideration), collective morale and participation (cooperation). The present study aims to investigate the relationship between work ethics and human resources productivity and presents some solutions to develop efficiency and effectiveness in organization.

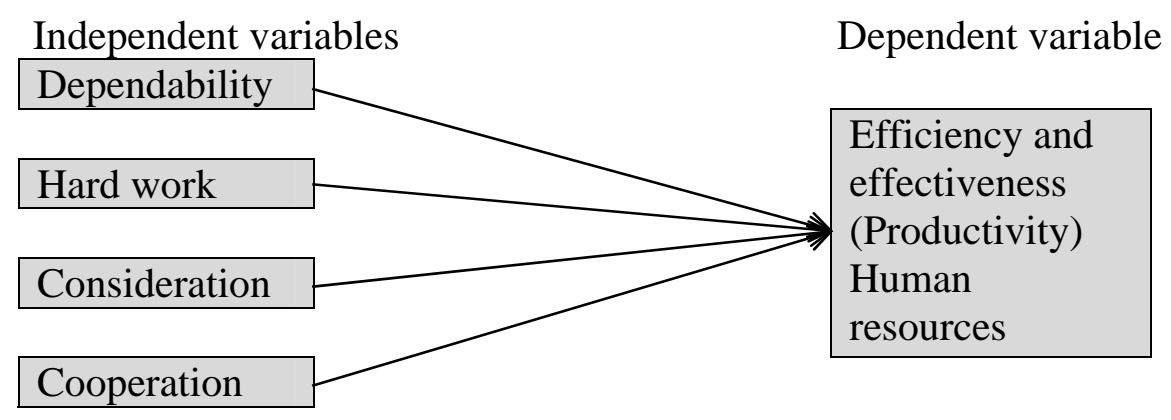

Fig. 1. Conceptual model of the study

Productivity: It is optimal use of various resources to produce the goods and services attracting the consumers' satisfaction, maximize job satisfaction of the employees and increase the desirability of the employees' lives in all its aspects (Saatchi, 2003).

Work ethics: It is a field of culture including the values and beliefs of work and it can be identified. Work ethics follows the general rules of the culture and society. Work ethics of asset has various dimensions including dependability, hard work, consideration and cooperation.

\section{Study hypotheses}

\subsection{Main hypothesis}

There is a significant association between work ethics and productivity of human resources.

\subsection{Sub-hypothesis}

There is a significant association between "dependability" and "efficiency and effectiveness of human resources”.

There is a significant association between "hard work" and "efficiency and effectiveness of human resources”.

There is a significant association between "consideration" and "efficiency and effectiveness of human resources". 
There is a significant association between "cooperation" and "efficiency and effectiveness of human resources”.

\section{Study method}

The present study is applied and it can be used in state organizations and companies in Iran and it is descriptive-correlation in terms of study method. The study population includes all employees of bank in city of Zahedan in 2013 and the study selected 236 people by random sampling. The study instrument in the present study was a 70-item questionnaire to investigate the relationship between work ethics of the employees and productivity of human resources. 50 questions are dedicated to work ethics factors and 21 questions are about human resources productivity. Work ethics questionnaire of Trianosky (1990), productivity questionnaire (efficiency and effectiveness) is based on Salajeghe et al. (2010) research investigating the relationship between work life quality and human resources productivity in health service centers (case study: nurses of Shahid Sadughi hospital in Yazd) and its validity was supported. To evaluate the reliability of the questionnaire, Cronbach's alpha was used and the reliability of the questionnaire of work ethics and human resources productivity were calculated and presented in Table 1, which shows high reliability of measurement instrument.

\section{Table 1}

Cronbach's alpha of independent and dependent variables

\begin{tabular}{lll}
\hline Variable & Questions & Reliability \\
\hline Work ethics & 50 & 0.91 \\
Dependability & 16 & 0.87 \\
Hard work & 12 & 0.75 \\
Consideration & 14 & 0.78 \\
Cooperation & 8 & 0.89 \\
Human productivity & 21 & 0.88 \\
\hline
\end{tabular}

The data analysis of the study was accomplished by SPSS software at descriptive (e.g. frequency, percent, mean, SD, and inference statistics was used as the data are quantitative, Pearson correlation was used to examine the hypotheses. Correlation analysis is used to evaluate the significant association between work ethics and human resources productivity components. Friedman ranking test is used to prioritize the productivity components and work ethics and independent t-test was also applied. Fig. 2 shows personal characteristics of the participants. As we can observe from the results of figure, nearly $60 \%$ of the participants were middle aged men and most of the participants hold university degrees.

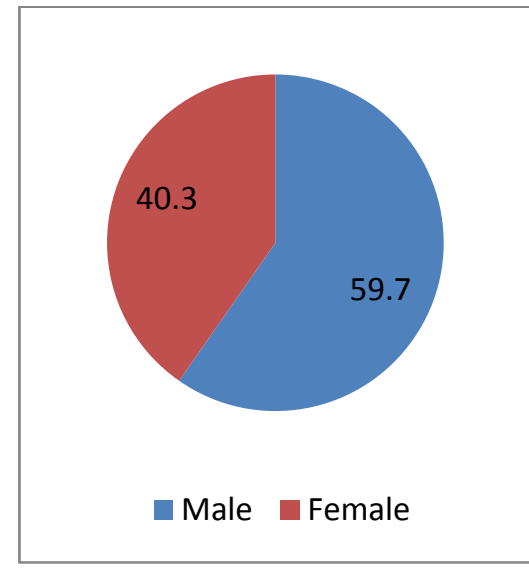

Gender

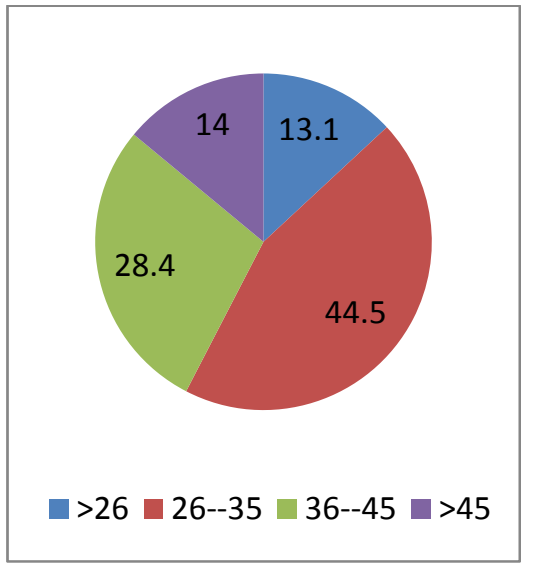

Age

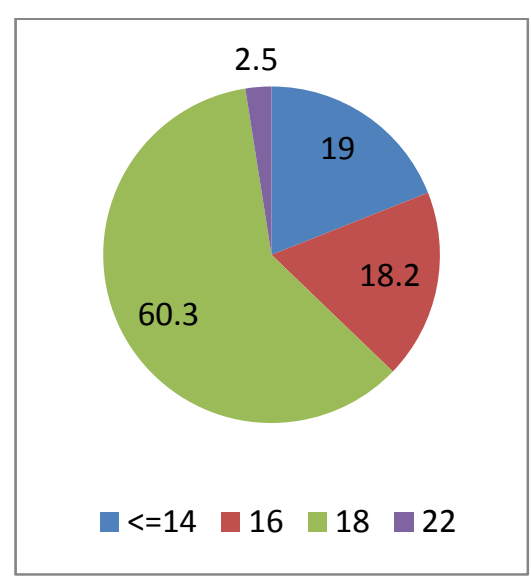

Years of educations

Fig. 2. Personal characteristics of the participants 


\section{The results}

\subsection{The results of testing hypotheses by Pearson correlation coefficient test}

Table 2 shows details of our findings on testing the main hypothesis as well as sub-hypotheses of the survey.

\section{Table 2}

Correlation coefficient between the study variables

\begin{tabular}{|c|c|c|c|}
\hline Study hypotheses & Coefficient & Sig. & Results \\
\hline First hypothesis: Between ethics and productivity & 0.608 & 0.01 & Supported \\
\hline $\begin{array}{l}\text { There is an association between dependability and human resources } \\
\text { productivity. }\end{array}$ & 0.568 & 0.01 & Supported \\
\hline $\begin{array}{l}\text { There is an association between hard work and human resources } \\
\text { productivity. }\end{array}$ & 0.480 & 0.01 & Supported \\
\hline $\begin{array}{l}\text { There is an association between consideration and human resources } \\
\text { productivity. }\end{array}$ & 0.506 & 0.01 & Supported \\
\hline $\begin{array}{l}\text { There is an association between cooperation and human resources } \\
\text { productivity. }\end{array}$ & 0.542 & 0.01 & Supported \\
\hline
\end{tabular}

As shown in Table 2, there is a positive and significant association between work ethics and human resources productivity $(\mathrm{r}=0.608$, Sig. $=0.01)$, dependability $(\mathrm{r}=0.568$, Sig. $=0.01)$, hard work $(\mathrm{r}=0.480$, Sig. $=0.000)$, consideration $(\mathrm{r}=0.506$, Sig. $=0.000)$ and cooperation $(\mathrm{r}=0.542$, Sig. $=0.000)$. It means that an increase of work ethics also increase human resources productivity. According to the results of the table, among the work ethics components, dependability have the great effect and work hard has the lowest effect on human resources productivity in an organization.

\subsection{Friedman test for ranking work ethics components}

In order to understand more about the effects of various ethics components the study uses Freedman test and Table 3 shows details of our findings.

\section{Table 3}

The results of ranking work ethics component

\begin{tabular}{lcc}
\hline Components & Mean rank & Significance level \\
\hline Dependability & 2.39 & \\
Consideration & 2.96 & 0.001 \\
Hard work & 2.18 & \\
Cooperation & 2.47 & \\
\hline
\end{tabular}

As shown, consideration component has the highest mean rank and hard work had the lowest mean rank.

\subsection{Friedman test to rank human resources productivity components}

\section{Table 5}

The results of ranking human resources productivity component

\begin{tabular}{llc}
\hline Components & Mean rank & Significance level \\
\hline Job satisfaction & 2.43 & \\
Organizational commitment & 1.97 & 0.001 \\
Creativity and innovation & 1.60 & \\
\hline
\end{tabular}


As shown in table 5, job satisfaction maintains the highest mean rank followed by creativity and innovation.

\subsection{Testing the effect of gender on ethics}

In order to understand the effect of gender on ethics, the study uses t-student test and Table 5 demonstrates the results of our investigation.

\section{Table 5}

The work ethics condition based on gender

\begin{tabular}{lccccccc}
\hline Gender & $\mathrm{N}$ & Mean & SD & Variable & t & df & Sig. \\
\hline Man & 141 & 15.0755 & 2.97 & Work ethics & 2.61 & 169.91 & 0.05 \\
Woman & 98 & 13.8223 & 3.62 & & & & \\
\hline
\end{tabular}

Based on the results of Table 5, there is a significance difference between gender and work ethics.

\subsection{Testing the effect of gender on productivity}

Similarly, In order to understand the effect of gender on ethics, the study uses t-student test and Table 6 demonstrates the results of our investigation.

\section{Table 6}

The work ethics condition based on gender

\begin{tabular}{lccccccc}
\hline Gender & $\mathrm{N}$ & Mean & SD & Variable & t & df & Sig. \\
\hline Man & 141 & 10.485 & 1.953 & Productivity & -1.62 & 138 & 0.85 \\
Woman & 98 & 10.9963 & 1.883 & & & & \\
\hline
\end{tabular}

Based on the results of Table 6, there is not any significant difference between gender and human resources productivity.

\section{Discussion, conclusion and recommendations}

The results of this study are in line with the results of the previous studies mentioned earlier. In terms of work ethics, the study has reported its important role as a factor for improving human resources' productivity as well as improving total productivity of organization. Most of the behaviors and decisions of the employees and managers in current organizations are affected by their ethical values. As human resources at individual and group level is the most important factor of competitive advantage, people judgment of the truth or falseness of the tasks is effective on the quality and quantity of their performance and organization performance and its success. Thus, considering ethical principles is an unavoidable necessity for the organizations. Based on the role and importance of human resources productivity in determining and predicting work ethics, managers need to consider this issue. It can prepare the organization space for productive work and the employees expect they are behaved respectfully and nothing is harmful than the work ethics of the employees and this belief that the organization gives no importance for the health of employees. The manager should attempt to give rewards for the good performance of the employees and by motivational programs. They also need to take ethics field decisions in a group to increase employees' respects. When the employees perform an ethical work, they are encouraged by the top managers to improve the probability of doing other ethical works as the ethical work becomes an internal value.

\section{Acknowledgement}

The authors would like to thank the anonymous referees for constructive comments on earlier version of this paper. 


\section{References}

Alvani, S.M., \& Danayifard, H. (2001). Some speeches about the philosophy of state organizations theories. $2^{\text {nd }}$ ed., SAMT, Tehran.

Deshpande, S. P., \& Joseph, J. (2009). Impact of emotional intelligence, ethical climate, and behavior of peers on ethical behavior of nurses. Journal of Business Ethics, 85(3), 403-410.

Eltantawy, R. A., Giunipero, L., \& Fox, G. L. (2009). A strategic skill based model of supplier integration and its effect on supply management performance.Industrial Marketing Management, 38(8), 925-936.

Floridi, L. (1999). Information ethics: on the philosophical foundation of computer ethics. Ethics and information technology, 1(1), 33-52.

Ghahremani, J. \& GholiGhourchian, N. (2012). Investigating effective factors on the teacher's work ethics of three educational levels to represent a model. American Journal of Scientific Research, 54, 101-110.

Haghiri, A. (2009). The relationship between managers' ethics with employee organizational commitment and job involvement in school districts in Semnan province. (Master thesis).Garmsar: Islamic Azad University Garmsar branch.

Hamidifar, F. (2009). A study of the relationship between leadership styles and employee job satisfaction at Islamic Azad University branches in Tehran, Iran.AU-GSB e-Journal, 1-13.

Jolayi, S., Jalili, H., Rafie, F., Haghani, H., \& Haj Babayi, F. (2011). The study of ethical climate relationship at work place of the nurses and their job satisfaction in selected sectors of educational-health centers of Medical Sciences University of Tehran in 2009. Journal of Medical Ethics, 5(15), 11-24.

Karimi, M., Rajayipour, S., \& Hoveida, R. (2010). The study of the relationship between organizational climate dimensions and ethical behavior among the staffs of Isfahan and Medical sciences University. Leadership and Educational Management Journal. 4(1), 83-102.

Khatami Firoozabadi, A., \& Heidari, A. (2012). The identification and ranking stressful organizational factors in industrial environments with fuzzy AHP. Research in Operation and its Applications Journal. 9(1), 105-115.

Larbi, G. (2001). Assessing infrastructure for managing ethics in the public service in Ethiopia: challenges and lessons for reformers. International review of administrative sciences, 67(2), 251262.

Martin, K. D., \& Cullen, J. B. (2006). Continuities and extensions of ethical climate theory: A metaanalytic review. Journal of Business Ethics, 69(2), 175-194.

Nosratpanah, S., Hassani, K., \& Yazdani, O. (2012). A study on the relationship between work life quality and human resources productivity. Journal of Human Resources Management.

Okpara, J. O., \& Wynn, P. (2008). The impact of ethical climate on job satisfaction, and commitment in Nigeria: Implications for management development. Journal of Management Development, 27(9), 935-950.

Pettijohn, C., Pettijohn, L., \& Taylor, A. J. (2008). Salesperson perceptions of ethical behaviors: Their influence on job satisfaction and turnover intentions. Journal of Business Ethics, 78(4), 547557.

Pournaghdi, B. (2009). Ethics in IT and pathology of communication ethics. Ethics in Sciences and Technology. 1(2), 21-28.

Ronaghi, M.H., Feizi, K. (2012). Work ethics and its relationship with information security management. Ethical Knowledge. 11(3), 95-105.

Saatchi, M. (1991). Psychology at work. Management organization. $2^{\text {nd }}$ ed. Tehran.

Sabori, D. (2010). The relationship ethical behavior of managers with model of consumption behavior in public organizations. (Master thesis). Garmsar: Islamic Azad University Garmsar Branch. 
Salajeghe, S., Sistani, F. (2010). The study of the relationship between work ethics and services quality in state organizations of Kerman. National conference of management and leadership challenges in Iranian organizations.

Sohrabi, B., \& Khanlari, A. (2009). IT ethics and organizational citizenship behavior. Journal of Ethics in Technology Sciences, 1(2). 1-10.

Tulayi, R. (2008). The effective factors on ethical behavior of the employees in organization. Scientific-Promotion Journals of Police Human Resources Development, 25.

Trianosky, G. (1990). What is virtue ethics all about?. American Philosophical Quarterly, 27(4), 335344. 